\title{
Digestibilidade da silagem de grãos úmidos de milho com diferentes granulometrias para suínos
}

\author{
[Digestibility of high moisture corn grain silage with different particle size for swines] \\ A.C. Lohmann ${ }^{1}$, P.C. Pozza ${ }^{2}$, R.V. Nunes ${ }^{2}$, M.S.S. Pozza ${ }^{2}$, I. Venturi ${ }^{3}$, T.J. Pasquetti ${ }^{3}$ \\ ${ }^{1}$ Aluno de pós-graduação - CCA-UNIOESTE - Marechal Cândido Rondom, PR \\ ${ }^{2}$ Centro de Ciências Agrárias - UNIOESTE - Marechal Cândido Rondom, PR \\ ${ }^{3}$ Aluno de graduação - UNIOESTE - Marechal Cândido Rondom, PR
}

\begin{abstract}
RESUMO
Avaliou-se a composição química e determinaram-se os valores de energia digestível (ED) e metabolizável (EM), os coeficientes de digestibilidade da matéria seca (CDMS), da proteína bruta (CDPB), da matéria mineral (CDMM); do extrato etéreo (CDEE); da fibra bruta (CDFB), da energia bruta (CDEB) e do extrativo não nitrogenado (CDENN) e os coeficientes de digestibilidade (CDEB) e metabolizabilidade da energia bruta (CMEB) da silagem de grãos úmidos de milho (SGUM). Foram utilizados 20 suínos, com peso vivo inicial de $28,89 \pm 4,9 \mathrm{~kg}$, distribuídos em gaiolas de metabolismo. Foi utilizada uma única SGUM, com quatro diferentes granulometrias 513, 587, 717 e $1363 \mu \mathrm{m}$, que substituiu em $30 \%$ a dieta-referência. Os CDMS, CDPB, CDEE, CDMM e CDENN diminuíram com o aumento da granulometria da SGUM. Os CDEB e CMEB também diminuíram de 89,0 para $94,3 \%$, e de 82,9 para $88,5 \%$, respectivamente. Os valores energéticos variaram de 4439 a $4493 \mathrm{kcal} \mathrm{EB} / \mathrm{kg}$, de 3999 a $4194 \mathrm{kcal} \mathrm{ED} / \mathrm{kg}$ e de 3729 a $3939 \mathrm{kcal} \mathrm{EM} / \mathrm{kg}$, na matéria seca. Os CDEB e CMEB se reduziram até os diâmetros geométricos médios de 754 e $831 \mu \mathrm{m}$, respectivamente. A digestibilidade dos nutrientes da SGUM foi influenciada negativamente ao se aumentar o diâmetro geométrico médio das partículas.
\end{abstract}

Palavras-chave: suíno, grão de milho, silagem, digestibilidade, composição química, diâmetro geométrico médio

\begin{abstract}
The chemical composition; the values of digestible $(D E)$ and metabolizable $(M E)$ energy; the coefficients of digestibility of dry matter (CDDM), crude protein (CDCP), mineral matter (CDMM), ether extract (CDEE), crude fiber (CDFB), crude energy (CDCE), and non nitrogen extractive (CDENN); as well as the coefficient of metabolizability of gross energy (CMGE) of high moisture corn grain silage (HMCGS) were evaluated. Twenty swines, averaging $28.89 \pm 4.9 \mathrm{~kg}$ of live weight, randomly allotted in metabolism cages were used. HMCGS with

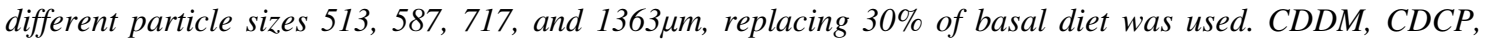
CDEE, CDMM, and CDENN decreased as the particle size of the HMCGS increased. CDGE and CMGE also decreased from 89.0 to $94.3 \%$ and from 82.9 to $88.5 \%$, respectively. The energy values varied from 4,439 to $4,493 \mathrm{kcal}$ of $\mathrm{GE} / \mathrm{kg}, 3,999$ to $4,194 \mathrm{kcal} \mathrm{DE} / \mathrm{kg}$, and 3,729 to 3,939kcal ME/kg, in dry matter basis. CDGE and CMGE decreased until the medium geometric diameters of 754 and $831 \mu \mathrm{m}$, respectively, and the digestibility of the nutrients of the HMCGS was negatively influenced as the medium geometric diameter of the particles increased.
\end{abstract}

Keywords: swine, corn grain, silage, digestibility, chemical composition, geometric diameter

\section{INTRODUÇÃO}

O milho tem sido a principal fonte energética utilizada na alimentação de suínos e é responsável pela maior parte dos custos com a produção de rações. Diante disso, a busca de alimentos alternativos é uma preocupação constante dos pesquisadores, que visa otimizar os índices produtivos e econômicos nos sistemas de exploração pecuários.

Recebido em 17 de setembro de 2009

Aceito em 2 de fevereiro de 2010

E-mail: andre22acl@yahoo.com.br 
A silagem de grãos úmidos de milho (SGUM) está sendo, cada vez mais, utilizada no Brasil, apresenta vantagens em relação ao milho seco, tais como: a antecipação da colheita, a liberação da terra para outras culturas, a utilização de um sistema de armazenamento mais simples, permitindo aos produtores estocar os grãos em suas propriedades de uma maneira prática e econômica, podendo ser produzida na própria propriedade e, além disso, sem alterar os valores nutricionais do milho (Reis et al., 2001). A composição química da SGUM pode variar em função do teor de umidade, no momento da ensilagem, e da proporção de sabugo presente, entre outros fatores (Jobim et al., 1997).

Ao avaliar quatro diferentes cultivares de milho, utilizados no preparo de SGUM, Schumacher (2004) obteve valores de energia digestível inferiores $(3494,3611,3681,3701 \mathrm{kcal} / \mathrm{kg}$ MS) em relação ao valor observado por Oliveira (2002), que foi de $3969 \mathrm{kcal} / \mathrm{kg}$ MS. Lima et al. (1999), ao avaliarem duas SGUM, encontraram valores ainda maiores, 4070 e $4123 \mathrm{kcal} / \mathrm{kg}$ MS. Os valores de energia metabolizável obtidos por Schumacher (2004) também foram inferiores (3392, 3432, 3570 e $3613 \mathrm{kcal} / \mathrm{kg}$ MS) aos encontrados por Lima et al. (1999), que foram de 3929 e $3990 \mathrm{kcal} / \mathrm{kg}$ MS para duas diferentes SGUM, e por Oliveira (2002), que foi de $3866 \mathrm{kcal} / \mathrm{kg} \mathrm{MS}$.

As diferenças observadas entre os valores de energia digestível (ED) e de energia metabolizável (EM) podem ser atribuídas, segundo Lima et al. (1999), ao conteúdo de proteína bruta do alimento. No entanto, os valores de PB encontrados por Schumacher (2004), com pequena variação entre as SGUM, estão dentro dos valores citados na literatura. Esse autor não observou diferenças significativas entre os cultivares de milho avaliados em relação aos coeficientes de digestibilidade e metabolizabilidade da energia bruta. As diferenças entre os valores ED e EM podem ser atribuídas ao diâmetro geométrico médio (DGM), pois partículas maiores de pericarpo são mais resistentes à degradação microbiana e à digestão enzimática no intestino delgado (Lima et al., 1999).

De acordo com Wondra et al. (1995), a moagem do milho com peneiras com diâmetro dos furos de $1,00,0,80,0,60$ e $0,40 \mathrm{~mm}$ não influenciou o consumo de alimento, mas a redução das partículas do milho melhorou de forma linear a eficiência alimentar, de forma quadrática a digestibilidade da energia bruta e reduziu de forma linear a excreção de matéria seca e nitrogênio.

Os objetivos deste trabalho foram avaliar a composição química, determinar os valores de energia digestível e metabolizável, os coeficientes de digestibilidade da proteína bruta, da matéria seca, da matéria mineral, do extrato etéreo, da fibra bruta e do extrativo não nitrogenado, assim como o coeficiente de metabolizabilidade da energia bruta de silagem de grãos úmidos de milho, com diferentes granulometrias, para suínos.

\section{MATERIAL E MÉTODOS}

Foram utilizados 20 suínos, mestiços, machos castrados, com média de peso vivo inicial de $28,89 \pm 4,9 \mathrm{~kg}$, distribuídos individualmente em gaiolas de metabolismo, em um delineamento experimental de blocos ao acaso, constituído de cinco tratamentos e quatro repetições. Na formação dos blocos, considerou-se o efeito temporal, uma vez que foram alojados dez animais de cada vez. O período experimental teve a duração de 13 dias, sendo sete dias de adaptação dos animais às gaiolas de metabolismo e às rações e seis dias de coleta de fezes e urina.

A quantidade de ração fornecida diariamente foi calculada com base no tamanho metabólico $\left(\mathrm{kg}^{0,75}\right)$. Para evitar perdas, e facilitar a ingestão, as rações foram umedecidas e fornecidas duas vezes ao dia ( $7 \mathrm{~h} \mathrm{e} 30 \mathrm{~min}$ e $15 \mathrm{~h}$ e $30 \mathrm{~min}$ ). As coletas de fezes foram realizadas duas vezes ao dia, às oito e 16 horas, e a de urina uma vez, às oito horas. Para definir o início e o final do período de coleta, usou-se o óxido férrico $\left(\mathrm{Fe}_{2} \mathrm{O}_{3}\right)$ na ração.

Foi utilizada uma única SGUM, com quatro diferentes granulometrias, 513, 587, 717 e $1363 \mu \mathrm{m}$, que substituiu em $30 \%$ a ração referência à base de milho, farelo de soja, vitaminas, minerais e aminoácidos (Tab. 1), formulada para atender, no mínimo, às recomendações de Rostagno et al. (2000). A SGUM foi submetida à moagem em peneiras com diâmetros dos furos de 4, 6, 8 e $10 \mathrm{~mm}$, para obtenção dos tamanhos das partículas de 513, 587, 717 e $1363 \mu \mathrm{m}$, respectivamente. 
O amido também apresentou comportamento semelhante aos demais parâmetros da composição química, sendo que estes variaram de 74,8 a $74,9 \%$.

Esperava-se que a composição química das SGUM com diferentes DGM fosse a mesma. Essa variação pode ser devido a fatores físicos que podem provocar essas diferenças químicas, como estratificação das partículas e irregularidade na homogeneidade do material (Kutschenko, 2004).
As diferenças observadas entre os dados da composição química obtidos e os da literatura consultada podem ser atribuídas aos fatores genéticos da planta, à adubação utilizada (especialmente nitrogênio), à fertilidade do solo e às condições climáticas (Oliveira et al., 2004 e Silva et al., 2006). Costa et al. (1999) relataram, ainda, que, por ocasião da maturação fisiológica, os grãos apresentam teores máximos de amido, proteína e óleo.

Tabela 2. Composição química e coeficientes de digestibilidade da matéria seca (CDMS), da matéria mineral (CDMM), da proteína bruta (CDPB), do extrato etéreo (CDEE), da fibra bruta (CDFB) e do extrativo não nitrogenado (CDENN) da silagem de grãos úmidos de milho com diferentes granulometrias para suínos, na MS

\begin{tabular}{|c|c|c|c|c|c|}
\hline & \multicolumn{4}{|c|}{$\mathrm{DGM}(\mu \mathrm{m})$} & \multirow{2}{*}{$\mathrm{CV}(\%)$} \\
\hline & 513 & 587 & 717 & 1363 & \\
\hline$\overline{\mathrm{MS}(\%)^{1}}$ & 70,32 & 70,97 & 70,54 & 70,58 & - \\
\hline $\operatorname{CDMS}(\%)^{2}$ & 90,30 & 89,95 & 87,39 & 87,24 & 1,30 \\
\hline $\mathrm{MM}(\%)^{1}$ & 0,97 & 1,04 & 1,04 & 0,97 & - \\
\hline $\operatorname{CDMM}(\%)^{3}$ & 64,59 & 64,66 & 61,30 & 48,88 & 11,87 \\
\hline $\mathrm{PB}(\%)^{1}$ & 7,49 & 7,35 & 7,76 & 7,68 & - \\
\hline $\operatorname{CDPB}(\%)^{2}$ & 84,27 & 83,82 & 78,84 & 60,08 & 5,69 \\
\hline $\mathrm{EE}(\%)^{1}$ & 4,70 & 4,93 & 4,48 & 4,56 & - \\
\hline $\operatorname{CDEE}(\%)^{\mathrm{ns}}$ & 89,98 & 88,44 & 81,24 & 78,91 & 8,49 \\
\hline $\mathrm{FB}(\%)^{1}$ & 2,33 & 2,28 & 2,16 & 2,35 & - \\
\hline CDFB $(\%)^{\mathrm{ns}}$ & 32,53 & 33,58 & 26,52 & 27,84 & 41,38 \\
\hline $\operatorname{ENN}(\%)^{1}$ & 54,83 & 55,37 & 55,10 & 55,02 & - \\
\hline $\operatorname{CDENN}(\%)^{2}$ & 90,50 & 90,75 & 88,22 & 84,93 & 1,55 \\
\hline Amido & 74,90 & 74,80 & 74,87 & 74,94 & - \\
\hline
\end{tabular}

MS: matéria seca; MM: matéria mineral; PB: proteína bruta; EE: extrato etéreo; FB: fibra bruta; ENN: extrativo não nitrogenado; DGM: diâmetro geométrico médio.

${ }^{1}$ Valores expressos na matéria seca; ${ }^{2}$ Efeito linear $(\mathrm{P}<0,01)$; ${ }^{3}$ Efeito linear $(\mathrm{P}<0,05)$; ns: não significativo.

Os coeficientes de digestibilidade apresentaram diferenças significativas, à exceção do CDFB e do CDEE (Tab. 2). Os coeficientes de digestibilidade diminuíram com o aumento do DGM da SGUM (Fig. 1).

Os CDMS (Fig. 1) diminuíram $(\mathrm{P}<0,01)$ de 90,3 para $87,2 \%$ à medida que o DGM das partículas da silagem de grãos úmidos de milho aumentou. Tse et al. (2004) não observaram diferenças significativas entre os CDMS da SGUM com diferentes granulometrias para suínos. Os CDMS foram de 90,5; 89,8 e 87,1\% para os DGM de 979, 1168 e $2186 \mu \mathrm{m}$, respectivamente. Esta redução do CDMS está relacionada ao maior DGM das partículas de milho da silagem, resultando em maiores partículas de pericarpo, o qual é muito resistente à digestão enzimática no intestino delgado (Jobim et al., 2001a). O coeficiente de digestibilidade da matéria mineral (CDMM) também se reduziu de 64,7 para $48,9 \%$ $(\mathrm{P}<0,05)$. 


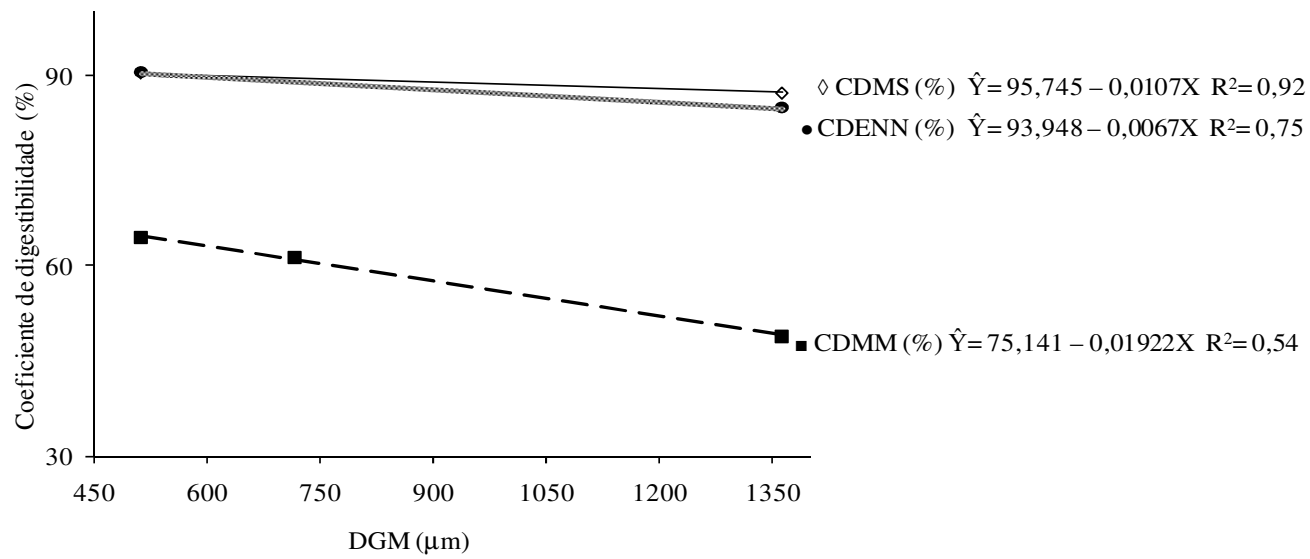

Figura 1. Coeficientes de digestibilidade da matéria seca (CDMS), da matéria mineral (CDMM), do extrato etéreo (CDEE), e do extrativo não nitrogenado (CDENN) em função de diferentes granulometrias (DGM) da silagem de grãos úmidos de milho para suínos.

O coeficiente de digestibilidade do extrato etéreo (CDEE), mesmo variando de 78,9 a 89,98\%, não apresentou diferença $(\mathrm{P}>0,05)$ entre os DGM da SGUM avaliada. Tófoli et al. (2004) verificaram CDEE de 77,9 e 75,2\%; esses valores foram, em média, mais baixos que os obtidos no presente trabalho.

Houve diferença no coeficiente de digestibilidade do extrativo não nitrogenado (CDENN) em função dos diferentes DGM $(\mathrm{P}<0,01)$, observando-se resposta inversamente proporcional, em que, à medida que os DGM aumentavam, o CDENN reduzia.

Quanto ao CDPB, pode-se observar que, à medida que o DGM aumentou, o CDPB reduziu (Fig. 2). Ao se considerar o modelo de regressão linear, verificou-se comportamento inversamente proporcional. No entanto, ao se considerar o modelo descontínuo (LRP), observa-se redução no CDPB até o DGM de $1204 \mu \mathrm{m}$, e, a partir deste ponto, não se observou a influência do DGM sobre o CDPB, estabelecendo-se um platô.

Tse et al. (2004), ao trabalharem com partículas maiores (979, 1168 e $2186 \mu \mathrm{m})$, não observaram efeito significativo do DGM da SGUM em relação ao CDPB. O menor CDPB obtido assemelha-se ao valor de $64,2 \%$ observado por Santos et al. (2002) para as SGUM, com DGM de $2077 \mu \mathrm{m}$. Silva et al. (2006) obtiveram CDPB de $83,9 \%$ para a SGUM com DGM de $967 \mu \mathrm{m}$, próximo aos CDPB de 84,3 e 83,8\% observados neste trabalho, para os DGM de 513 e $587 \mu \mathrm{m}$, respectivamente.

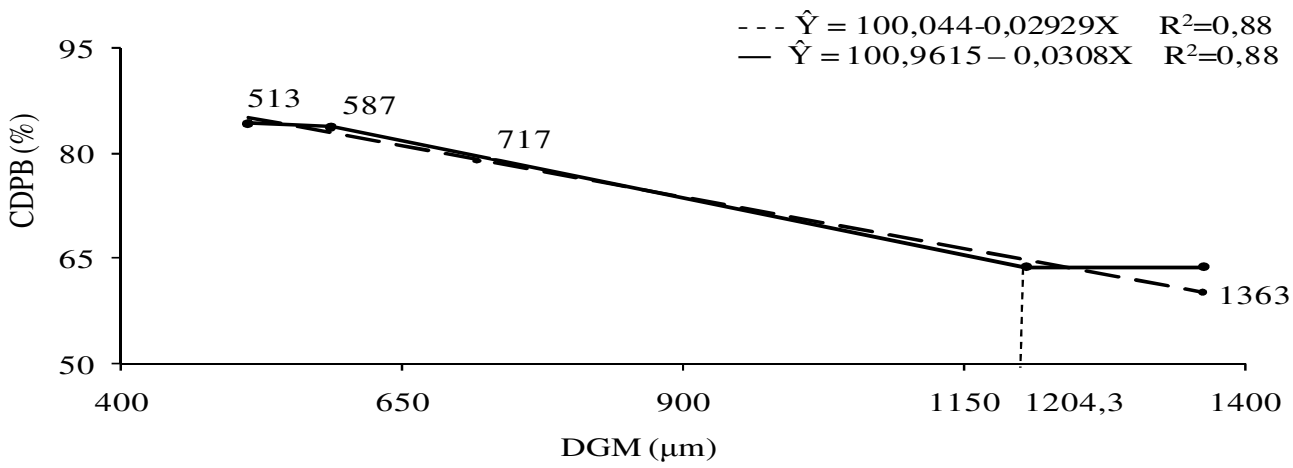

Figura 2. Coeficientes de digestibilidade da proteína bruta (CDPB) em função de diferentes granulometrias (DGM) da silagem de grãos úmidos de milho para suínos. 
Os valores de EB (Tab. 3) variaram de 4439 a $4493 \mathrm{kcal} / \mathrm{kg}$, com base na matéria seca. Oliveira et al. (2004) observaram valor de $4367 \mathrm{kcal}$ $\mathrm{EB} / \mathrm{kg}$, mais baixo que o verificado neste trabalho. Segundo esses autores, o milho utilizado pode ter sido colhido antes de a planta atingir a maturação fisiológica.

Foi observada diferença $(\mathrm{P}<0,05)$ entre os $\mathrm{CDEB}$ em função dos DGM avaliados, pois ocorreu diminuição linear do CDEB à medida que o DGM aumentou.

Ao se considerar o modelo LRP, observa-se redução no CDEB até o DGM de $754 \mu \mathrm{m}$. A partir desse ponto, o CDEB foi semelhante para os demais DGM avaliados (Fig. 3).

Oliveira et al. (2004) obtiveram CDEB de $90,9 \%$, para DGM de $1.501 \mu \mathrm{m}$, próximo aos valores de 91,5 e $89,0 \%$ obtidos neste trabalho para os DGM de 717 e $1363 \mu \mathrm{m}$, respectivamente. Os valores encontrados são semelhantes aos obtidos por Lima et al. (1998), que trabalharam com duas SGUM e obtiveram os CDEB de 90,8 e 91,0\%. Os CDEB obtidos para os maiores DGM $(587,717$ e $1363 \mu \mathrm{m})$ foram menores que $95,2 \%$ proposto pela Embrapa (Tabela..., 1991), no entanto a SGUM com um DGM de $513 \mu \mathrm{m}$ apresentou um CDEB semelhante.

Tabela 3. Coeficientes de digestibilidade (CDEB) e metabolizabilidade (CMEB) da energia bruta da silagem de grãos úmidos de milho com diferentes granulometrias (DGM) para suínos, na matéria seca

\begin{tabular}{|c|c|c|c|c|c|}
\hline & \multicolumn{4}{|c|}{ DGM $(\mu \mathrm{m})$} & \multirow{2}{*}{$\mathrm{CV}(\%)$} \\
\hline & 513 & 587 & 717 & 1363 & \\
\hline EB $(\mathrm{kcal} / \mathrm{kg})$ & 4449 & 4478 & 4439 & 4493 & - \\
\hline $\operatorname{CDEB}(\%)^{1,2}$ & 94,28 & 92,57 & 91,53 & 89,01 & 3,36 \\
\hline $\mathrm{ED}(\mathrm{kcal} / \mathrm{kg})$ & 4194 & 4146 & 4062 & 3999 & - \\
\hline $\operatorname{CMEB}(\%)^{1,3}$ & 88,53 & 87,49 & 84,89 & 82,89 & 2,24 \\
\hline EM (kcal/kg) & 3939 & 3918 & 3768 & 3724 & - \\
\hline $\mathrm{EL}(\mathrm{kcal} / \mathrm{kg})^{*}$ & 3141 & 3130 & 3013 & 2981 & - \\
\hline EM:ED & 0,94 & 0,94 & 0,93 & 0,93 & - \\
\hline
\end{tabular}

${ }^{1}$ Modelo descontínuo LRP $(\mathrm{P}<0,05) ;{ }^{2}$ Efeito linear $(\mathrm{P}<0,05) ;{ }^{3}$ Efeito linear $(\mathrm{P}<0,01) ; *$ Valor calculado; DGM: diâmetro geométrico médio.

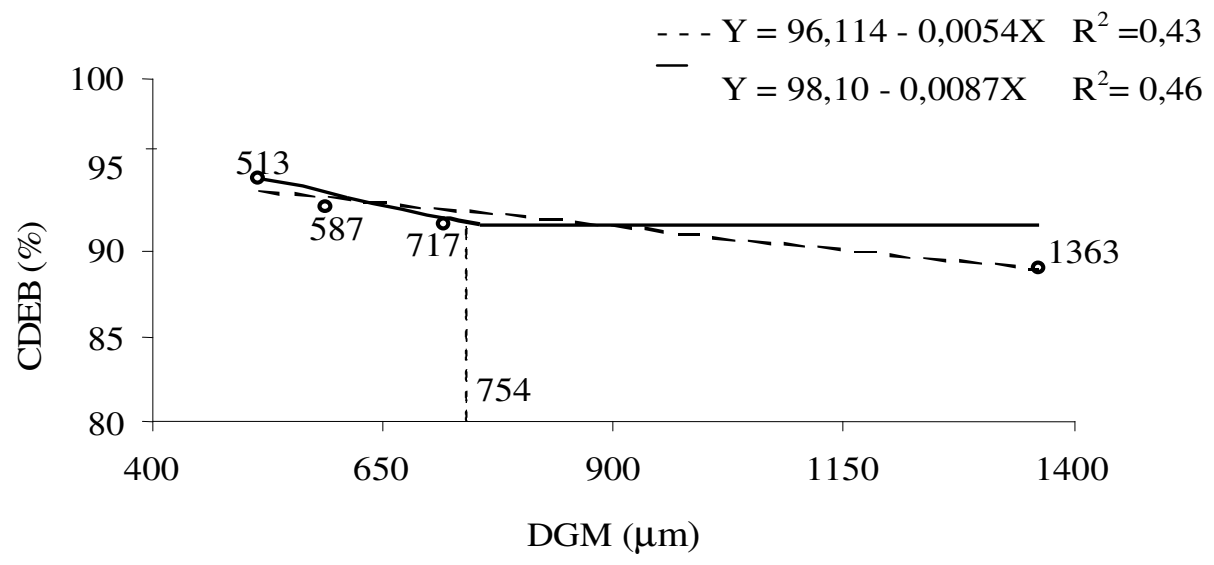

Figura 3. Coeficientes de digestibilidade da energia bruta (CDEB) em função de diferentes granulometrias (DGM) da silagem de grãos úmidos de milho para suínos. 
Os CMEB da SGUM apresentaram diferenças significativas $(\mathrm{P}<0,05)$. $\grave{A}$ medida que se aumentou o DGM, o CMEB reduziu linearmente. Conforme o modelo LRP, observa-se redução no CMEB até o DGM de $831 \mu \mathrm{m}$. A partir desse ponto, obteve-se a mesma resposta para o aumento do DGM (Fig. 4).
O CMEB da SGUM obtido por Oliveira et al. (2004) foi de $88,5 \%$, para um DGM de $1501 \mu \mathrm{m}$, aproximando-se do CMEB de 88,5 e $87,5 \%$ obtidos no presente trabalho, para os DGM de 513 e $587 \mu \mathrm{m}$, respectivamente. No entanto, Silva et al. (2006) obtiveram um CMEB de 88,3\%, semelhante aos obtidos para as granulometrias de 513 e $587 \mu \mathrm{m}$.

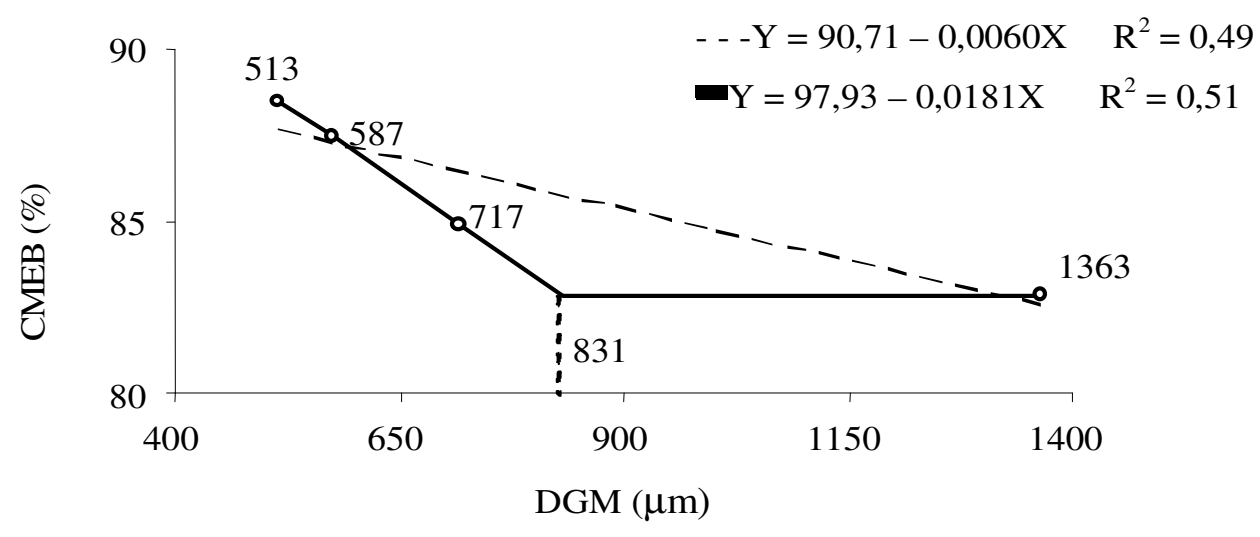

Figura 4. Coeficientes de metabolizabilidade da energia bruta (CMEB) em relação às diferentes granulometrias (DGM) da silagem de grãos úmidos de milho para suínos.

De maneira geral, foi observada redução linear no CDEB e no CMEB, e, ao se utilizar o modelo LRP, foram observadas reduções até os DGM de 754 e $831 \mu \mathrm{m}$, respectivamente, a partir do qual se estabeleceram os platôs. Os DGM de 754 e $831 \mu \mathrm{m}$ aproximam-se do DGM de $717 \mu \mathrm{m}$, que foi obtido ao se utilizar, na moagem, uma peneira com diâmetro dos furos de $8 \mathrm{~mm}$. Por outro lado, existe a recomendação de moagem dos grãos em peneira de $8 \mathrm{~mm}$ para uso na alimentação de suínos (Jobim et al., 2001b).

O menor valor de ED (Tab. 3), obtido com DGM de $1363 \mu \mathrm{m}$, encontra-se entre $3969 \mathrm{kcal} / \mathrm{kg}$ (Oliveira et al., 2004) e 4070kcal/kg (Lima et al., 1999), expressos na MS, relativo à SGUM com DGM de 1501 e $1236 \mu \mathrm{m}$, respectivamente. Tse et al. (2004) obtiveram uma variação de 4333 a $4163 \mathrm{kcal} / \mathrm{kg}$ ED, na MS, para SGUM com DGM de 979 e $2186 \mu \mathrm{m}$, respectivamente.

A EM foi menor, para a SGUM com DGM de 717 e $1363 \mu \mathrm{m}$, que as obtidas por Lima et al. (1999), Oliveira et al. (2004) e Tse et al., (2004), mas semelhantes para os DGM de 513 e $587 \mu \mathrm{m}$.
Os valores de ED e EM apresentaram redução de 195 e $215 \mathrm{kcal} / \mathrm{kg}$ de MS, respectivamente, referente ao aumento do DGM de 513 para $1363 \mu \mathrm{m}$. Essas reduções foram semelhantes às observadas por Tse et al. (2004), ao relatarem que a granulometria das silagens não influenciou os valores de ED e EM (P>0,05), apesar da diferença numérica de 170 e $200 \mathrm{kcal} / \mathrm{kg}$ de $\mathrm{MS}$, respectivamente, quando o DGM das partículas da silagem passou de 979 para $2186 \mu \mathrm{m}$.

Estes resultados corroboram os relatos de que os maiores valores energéticos encontrados para a SGUM podem, dentre outros, ser atribuídos à menor granulometria das partículas, por propiciar maior e mais rápida ação das secreções digestivas, aumentar a absorção e a retenção de nutrientes pelos suínos (Lima et al., 1999).

Os valores estimados de energia líquida (EL) (Tab. 3) variaram de 3141 a $2981 \mathrm{kcal} / \mathrm{kg}$ de MS, e foram inversamente proporcionais aos tamanhos das partículas das SGUM, seguindo o mesmo perfil dos valores de ED e EM. Isso foi atribuído à composição química das SGUM que 
apresentou pequena variação, associada ao fato de a EM apresentar grande expressão em seu produto final, na equação utilizada para estimar os valores de EL.

As relações EM:ED foram de 0,94 (513 e $587 \mu \mathrm{m})$ e $0,93(717$ e $1363 \mu \mathrm{m})$, observando-se menor relação para os maiores DGM. Oliveira et al. (2004), Tse et al. (2004) e Silva et al. (2006) observaram relações maiores EM:ED que variaram de 0,96 a 0,98 .

A pequena variação observada para a relação EM:ED pode estar associada à pequena variação do teor de PB da SGUM, por se tratar do mesmo alimento. Embora o CDPB tenha reduzido com o aumento do tamanho das partículas, indicando menor absorção de aminoácidos, obtiveram-se relações EM:ED semelhantes, talvez pelo fato de a redução dos valores de ED (195kcal $/ \mathrm{kg})$ e EM $(215 \mathrm{kcal} / \mathrm{kg})$ ter apresentado um perfil semelhante, influenciando diretamente a relação EM:ED.

\section{CONCLUSÕES}

A digestibilidade dos nutrientes da silagem de grãos úmidos de milho foi influenciada negativamente pelo diâmetro geométrico médio das partículas. Os coeficientes de digestibilidade e metabolizabilidade da energia bruta reduziram até os diâmetros geométricos médios de 754 e $831 \mu \mathrm{m}$, respectivamente.

\section{AGRADECIMENTOS}

À Fundação Araucária de Apoio ao Desenvolvimento Científico e Tecnológico do Paraná, pelo financiamento deste trabalho.

\section{REFERÊNCIAS BIBLIOGRÁFICAS}

COSTA, C.; ARRIGONI, M.D.B.; SILVEIRA, A.C. et al. Silagem de grãos úmidos. In: SIMPÓSIO SOBRE NUTRIÇÃO DE BOVINOS, 7., 1999, Piracicaba. Anais... Piracicaba: FEALQ. 1999. p.69-88.

JOBIM, C.C.; CECATO, U.; CANTO, M.W. Utilização da silagem de grãos de cereais na alimentação animal. In: SIMPÓSIO SOBRE PRODUÇÃO E UTILIZAÇÃO DE FORRAGEIRAS CONSERVADAS, 2001, Maringá. Anais... Maringá: Universidade Estadual de Maringá, 2001a. p.319. (Resumo).
JOBIM, C.C.; FURTADO, C.E.; SCAPINELLO, C. et al. Produção e utilização de silagem de grãos de cereais. In: SIMPÓSIO DE FORRAGICULTURA E PASTAGENS, 2, 2001, Lavras. Anais... Lavras: Universidade Federal de Lavras, 2001b. p.211-234.

JOBIM, C.C.; REIS, R.A.; RODRIGUES, L.R.A. Avaliação da silagem de grãos úmidos de milho. Pesq. Agropec. Bras., v.32, p.311-315, 1997.

KUTSCHENKO, M. Efeito de diferentes graus de moagem da casca de soja sobre a digestibilidade dos nutrientes e o desempenho de suínos na fase inicial. 2004. 41f. Dissertação (Mestrado) - Universidade Estadual de Maringá, Maringá, PR.

LIMA, G.J.M.M.; SOUZA, O.W.; BELLAVER, C. et al. Determinação da composição química e do valor energético de silagem de grãos úmidos de milho para suínos. In: CONGRESSO NACIONAL DE MILHO E SORGO, 22., 1998, Recife. Anais... Recife: ABMS, 1998. (CDROM) (Resumo).

LIMA, G.J.M.M.; SOUZA, O.W.; BELLAVER, C. et al. Composição química e valor energético de silagem de grão de milho para suínos. Concórdia: Embrapa Suínos e Aves, 1999. 2p. (Comunicado Técnico, n. 240).

NOBLET, J.; FORTUNE, H.; SHI, X.S. et al. Prediction of net energy value of feeds for growing pigs. J. Anim. Sci., v.72, p.344-354, 1994.

OLIVEIRA, R.P. Utilização da silagem de grãos úmidos de milho na alimentação de suínos em fase de creche. 2002. 46f. Dissertação (Mestrado) - Universidade Estadual de Maringá, Maringá, PR.

OLIVEIRA, R.P.; FURLAN, AC.; MOREIRA, I. Valor nutritivo e desempenho de leitões alimentados com rações contendo silagem de grãos úmidos de milho. Rev. Bras. Zootec., v.3, p.146-156, 2004.

REIS, W.; JOBIM, C.C.; MACEDO, F.A.F. et al. Características da carcaça de cordeiros alimentados com dietas contendo grãos de milho conservado em diferentes formas. Rev. Bras. Zootec., v.30, p.1308-1315, 2001. 
ROSTAGNO, H.S.; ALBINO, L.F.T.; DONZELE, J.L. et al. Tabelas brasileiras para aves e suínos; composição de alimentos $e$ exigências nutricionais. Viçosa, UFV, 2000. $141 \mathrm{p}$.

SANTOS, P.C.; FURTADO, E.C.; JOBIM, C.C. et al. Avaliação da silagem de grãos úmidos de milho na alimentação de equinos em crescimento: valor nutricional e desempenho. Rev. Bras. Zootec., v.31, p.1214-1222, 2002.

SCHUMACHER, G.C. Digestibilidade $e$ metabolizabilidade da energia bruta de diferentes silagens de grão úmido de milho para suínos. 2004. Trabalho de Conclusão de Curso (Zootecnia) - Universidade Estadual do Oeste do Paraná, Marechal Cândido Rondon, PR.

SILVA, A.A.; MARQUES, B.M.F.P.P.; HAUSCHILD, L. et al. Digestibilidade e balanços metabólicos da silagem de grãos úmidos de milho para suínos. Cienc. Rural, v.35., p.883-890, 2005.

SILVA, D.J.; QUEIROZ, A.C. Análise de alimentos: métodos químicos e biológicos. 3.ed. Viçosa, MG: UFV, 2002. 235p.

SILVA, M.A.A.; FURLAN, A.C.; MOREIRA, I. et al. Avaliação nutricional do milho com maior teor de óleo, nas formas de grãos secos e silagens, para suínos nas fases de crescimento e terminação. Rev. Bras. Zootec., v.35, p.830-839, 2006.
SISTEMA de análises estatísticas e genéticas SAEG. Viçosa: UFV, 1997.

TABELA de composição química e valores energéticos de alimentos para suínos e aves. 3.ed. Concórdia: Embrapa Suínos e Aves, 1991. p.97.

TÓFOLI, C.A., BERTO, D.A., TSE, M.L.P., et al. Digestibilidade da silagem de grãos úmidos de milho com diferentes teores de óleo em leitões na fase de creche. In: CONGRESSO LATINO AMERICANO DE SUINOCULTURA, 2., 2004, Foz do Iguaçu. Anais... Foz do Iguaçu: [s.n.], 2004. p.428-429.

TSE, M.L.P.; BERTO, D.A.; TÓFOLI, C. A. et al. Digestibilidade da silagem de grãos úmidos de milho com diferentes graus de moagem em leitões na fase de creche. In: CONGRESSO LATINO AMERICANO DE SUINOCULTURA, 2., 2004, Foz do Iguaçu. Anais... Foz do Iguaçu: [s.n.], 2004. p.433-434.

WONDRA, K.J.; HANCOCK, J.D.; KENNEDY, G.A. et al. Reducing particle size of corn in lactation diets from 1200 to 400 micrometers improves sow and litter performance. J. Anim. Sci., v.73, p.421-426, 1995.

ZANOTTO, L.D.; BELLAVER, C. Método de determinação da granulometria de ingredientes para uso em rações de suínos e aves. Concórdia: Embrapa Suínos e Aves, 1999. 5p. (Comunicado Técnico, n. 215). 